\title{
The Efficacy of Levator Tucking in Management of Congenital Ptosis: Tripoli-Libya
}

\author{
Dr. Juma Omrani ${ }^{1,2}$, Dr. Shaban Majdob ${ }^{1,2}$, Dr. Mansour Jnef ${ }^{1,2}$, Dr. Amal Elbahi ${ }^{1,2}$ \\ ${ }^{1}$ Tripoli Eye Hospital, ${ }^{2}$ Tripoli University
}

doi: $10.51505 / \mathrm{ijmshr} .2022 .6101$

URL: http://dx.doi.org/10.51505/ijmshr.2022.6101

\section{Abstract \\ Objective:}

To evaluate the efficacy of the levator tucking in correction of different degrees of congenital ptosis.

\section{Design:}

This is a prospective interventional case series study. Patients with unilateral ptosis or bilateral ptosis were operated upon between January 2020 and January 2021. All patients were evaluated and operated by one surgeon (Dr.Juma Omrani) and followed up for an average period of 6 months.

\section{Patients and methods:}

A22 eyes with ptotic eyelid of 20 patients were included in this study between January 2020 and January 2021. The patients ( 15 females and 5 males of age between 4 and 18 years old) were presented to the of Ophthalmology department Alsalam medical center, Libyan Swiss medical center and Tripoli eye hospital. Following ophthalmological and general evaluation 4 patients were operated upon under local anesthesia (age between 16 and 18), 16 patients were operated upon under general anesthesia (age between 4 and 16). Levator tucking was done through the skin side using nonabsorbable sutures. preoperative, intra-operative and postoperative photos were taken. Patients were followed up for an average period of 6 months. The results were analyzed for the efficacy of the procedure in correcting the ptotic eyelid.

\section{Results:}

22 eyelids of different degrees of ptosis underwent levator tucking; corrected in 19 cases (86\%), under corrected in 2 cases (9\%) and over corrected in 1 case (5\%).

\section{Conclusion:}

In this procedure the levator muscle was not severed and the horns where not cut which means there was no tissue destruction and the anatomy of the eyelids was not disturbed that much. Consequently, more anatomical and physiological repair was achieved. Therefore, this technique is safe, fast, simple and effective for management of congenital ptosis.

Keywords: Congenital Ptosis, Levator muscle, Tucking, Surgery. 


\section{International Journal of Medical Science and Health Research}

Vol. 6, No. 01; 2022

ISSN: $2581-3366$

\section{Introduction}

Ptosisis one of the most common eyelid disorders encountered in Ophthalmology. Ptosis refers to vertical narrowing of the palpebral fissure secondary to drooping of the upper eyelid to a lower than normal position. It is considered congenital if present at birth or if it is diagnosed within the first year of life. Congenital ptosis is generally unilateral (70\%), but maybe bilateral and can be isolated or associated with disease of one or more of the extraocular muscle and/or other systemic conditions ${ }^{1,2}$. Primary congenital ptosis tends to be non- Progressive. There is a Harmony between its severity and levator function. Commonly, it is due to the poor development of the levator muscle or its replacement by fibrosis, fat or areolar tissue. Amblyopia is rare in congenital ptosis unless it is associated with severe unilateral ptosis, anisometropia or strabismus ${ }^{3.4}$.

Anatomically, ptosis may be classified as neurogenic (third nerve palsy, Marcus Gunn jawwinking syndrome and Horner syndrome), myogenic (Myotonic dystrophy, ocular myopathy, myasthenia gravis, simple congenital, or blepharophimosis syndrome) and mechanical. Ptosis may be minimal (1-2 mm), moderate (3-4 mm) or severe (more than $4 \mathrm{~mm})^{5}$. Treatment of ptosis depends on age, etiology, wither one or both eyelids are involved, the severity of ptosis, the levator function and the presence of additional ophthalmologic or neurologic abnormalities.

Correction of congenital ptosis is one of the most difficult challenges ophthalmologists face. Multiple surgical procedures are available including frontalis sling, levator resection, levator tucking and Mullerectomy. Depending on the severity of congenital ptosis; the surgical correction can be undertaken at any age. Earlier intervention for significant amblyopia or ocular torticollis ${ }^{6,7}$. Ptosis surgery in young patients is different from other surgery in that predictability of lid height in later group could be enhanced by using local anesthesia or adjustable sutures ${ }^{8,9,10}$.

\section{Patients and Methods:}

In a prospective Interventional case series study, 22eyes of 20 patients were included after Ophthalmological and general evaluation. The patients, (15 females and 5 males of age between 4 and 18 years old) were presented to the Ophthalmology Department, Alsalam medical center and Libyan swiss medical center between Jan 2020 and Jan 2021 with average period of follow up of six months.

The included patients presented with unilateral isolated ptosis in 18 cases and bilateral ptosis in 2 cases. Ptosis was of varying degrees (mild, moderate or severe) and the main complaint was cosmetics (drooping of the upper eyelid).

The enrolled patients were with isolated simple congenital ptosis of different degrees. Patients with previous surgery, associated syndromes, or ptosis secondary to other causes were excluded from this study.

The patients were thoroughly examined to evaluate and determine the degree of ptosis, levator function, lid crease, corneal sensation, Bell's phenomenon, associated extraocular muscle palsy, visual acuity, best corrected vision, pupillary reaction and fundus examination. 


\section{International Journal of Medical Science and Health Research}

Vol. 6, No. 01; 2022

ISSN: $2581-3366$

The degree of ptosis was determined by measuring the distance between the upper lid margin and central corneal light reflex MRD and classified into mild, (covering 1-2 mm) moderate, ( covering 3-4 $\mathrm{mm}$ ) and severe $>4 \mathrm{~mm}$ ( covering the pupil).

The levator function was evaluated by determining the degree of elevation. Lid elevation was measured lwith the ruler and recorded in millimeters of levator function and classified into poor (less than $4 \mathrm{~mm}$ ), fair (5-8 $\mathrm{mm}$ ) and good levator(more than $8 \mathrm{~mm}$ ).

Regarding the Bell's phenomenon; which is an essential preoperative assessment before ptosis surgery. Normal Bell's phenomenon was reported when there is an upward and outward movement of the eyes associated with eyelid closure.

Photographic documentation was a crucial step throughout the procedure; preoperative, intraoperative and postoperative. preoperative photography was done for the whole face and for both eyes to document the presence of ptosis, compare with the other eye and help to determine the degree of ptosis. Intra-operative photographs were taken for surgical steps. Postoperative photographs were taken to evaluate the surgical outcome.

The patients were evaluated generally for fitness for general anesthesia. After proper examination the surgical procedure was simply explained to the patient and/or their parents. Informed consent was obtained and the surgery was done.

\section{The surgical procedure:}

The surgery was done under general anesthesia in 16 patients and under local anaesthesia in 4 patients. The operative field was prepared and the lid incision was done at the level of the lid crease if present or by comparison to the other eye (usually 8-10 $\mathrm{mm}$ ). the orbicularis muscle was opened using Wiscott scissors. The skin and muscle where then dissected of the underlying levatoraponurosisup to the level of the preaponeuretic fat with the overlying septum. The septum was then incised towards its upper part and the prolapse preaponeuretic fat was retracted backwards and part of it was excised to avoid post operative puffy lid. Afterwards, levator tucking was done using three non absorbable sutures one central and another two lateral and medial to the central one to augment and give better contour. the levator folding is $4 \mathrm{~mm}$, for each $1 \mathrm{~mm}$ of ptosis according to the degree of levator power and the levator was fixed to the anterior surface of the tarsus. In cases operated under Local anaesthesia patients were asked to sit intraoperativly to assess the height and contour of the eyelid and then readjusted accordingly. The lid then was everted to ensure that the suture was not penetrating to avoid postoperative corneal erosion.

The crease was formed; the incision was closed and dressed with betadine $10 \%$ and thin layer of ointment. Postoperative cold compresses were done.

The parents were instructed about the post-operative treatment ointment (Dexamethasone and antibiotic combination), tears substitute and follow up times. They were clearly instructed about 
the risk of postoperative exposure and how to avoid by regular and frequent use of tears substitute during the day and eye ointment at bedtime.

Photos were taken postoperatively and patients were followed up for an average period of six months

\section{Results}

Twenty two eyelids of 20 patients were enrolled in the study; 15 girls (75\%) and five boys (25\%) with age ranging from 4 to 18years old (Figure 1 ). Patients presented with unilateral ptosis in 18 cases and bilateral ptosis in two cases. The patients were presented to the clinic complaining of drooping of the eyelid and inequality of the palpebral fissure in 18 cases and chin elevation in two cases with bilateral ptosis.

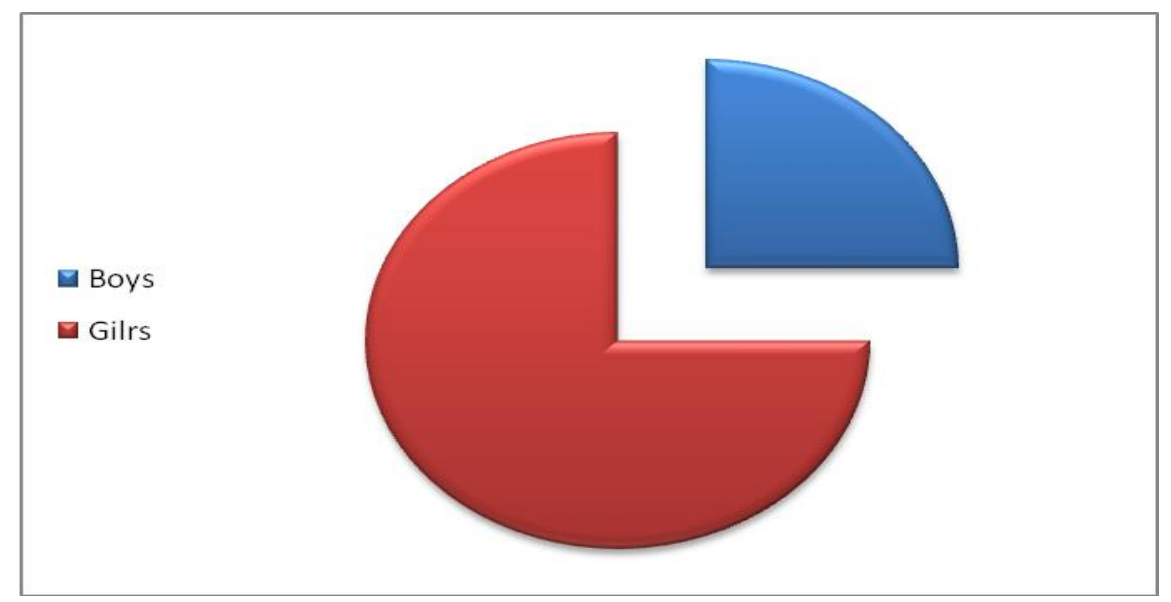

Figure (1): Sex distribution

The pre and post-operative results were evaluated by both clinical examination and photography (table $1 \& 2$ ) (Figure 2,3\&4).

\begin{tabular}{|l|l|}
\hline Postoperative result & Number of cases \\
\hline Degree of correction: & \\
\hline Corrected & 19 \\
\hline Under corrected & 2 \\
\hline Overcorrected & 1 \\
\hline Lid margin contour: & \\
\hline Adequate & 21 \\
\hline Notched & 1 \\
\hline Lid Oedema: & \\
\hline Resolved & 22 \\
\hline Persistent puffiness & 0 \\
\hline Eye closureAdequate & 22 \\
\hline Inadequate & 0 \\
\hline
\end{tabular}

Table (1) - Postoperative results of ptosis correction 


\begin{tabular}{|l|l|l|l|l|}
\hline Preoperative variable & corrected & Under- corrected & over-corrected & Total \\
\hline Degree of ptosis: & & & & \\
\hline Mild-Moderate & 16 & 1 & 1 & 18 \\
\hline Moderate-Severe & 3 & 1 & 0 & 4 \\
\hline $\begin{array}{l}\text { Degree of levator } \\
\text { function: }\end{array}$ & & & & \\
\hline Poor $(<4 \mathrm{~mm})$ & 3 & 1 & 0 & 4 \\
\hline Faire $(4-8 \mathrm{~mm})$ & 13 & 1 & 0 & 14 \\
\hline Good $(>8 \mathrm{~mm})$ & 3 & 0 & 1 & 4 \\
\hline
\end{tabular}

Table (2) - Postoperative results in relation to preoperative data

An 18 eyes showed mild to moderate degree of ptosisand 4 eyes were with moderate to severe ptosis. The levator function was less than $4 \mathrm{~mm}$ in 4 Eyes, $4-8 \mathrm{~mm}$ in 14 eyes and more than 8 $\mathrm{mm}$ in 4 eyes.

The surgical outcomes showed corrected eyelid position in 19 eyes (86\%)(within $1 \mathrm{~mm}$ from the other eyelid), under-corrected in 2 eyes (9\%) and overcorrected in one case (5\%). No eyelid puffiness in all cases.

Regarding the Contour of the lid margin, it was regular in 21 eyes and slightly notched in one case.

Inadequate lid closure especially during sleep was present in all cases within the early postoperative period and was improved within three months postoperatively in all cases.

Mild lid oedema was present in all eyes which resolved within the first week .over correction in 4 cases, 3 of them improved in 3 weeks, and one case needed revision. There were no cases of entropion, ectropion, or lash ptosis. Also, there were no cases of conjunctival prolapse or corneal exposure.

Contralateral drooping appeared or became more prominent postoperatively in 7 eyes which needed further interference for better cosmetic appearance. 
International Journal of Medical Science and Health Research

Vol. 6, No. 01; 2022

ISSN: 2581-3366

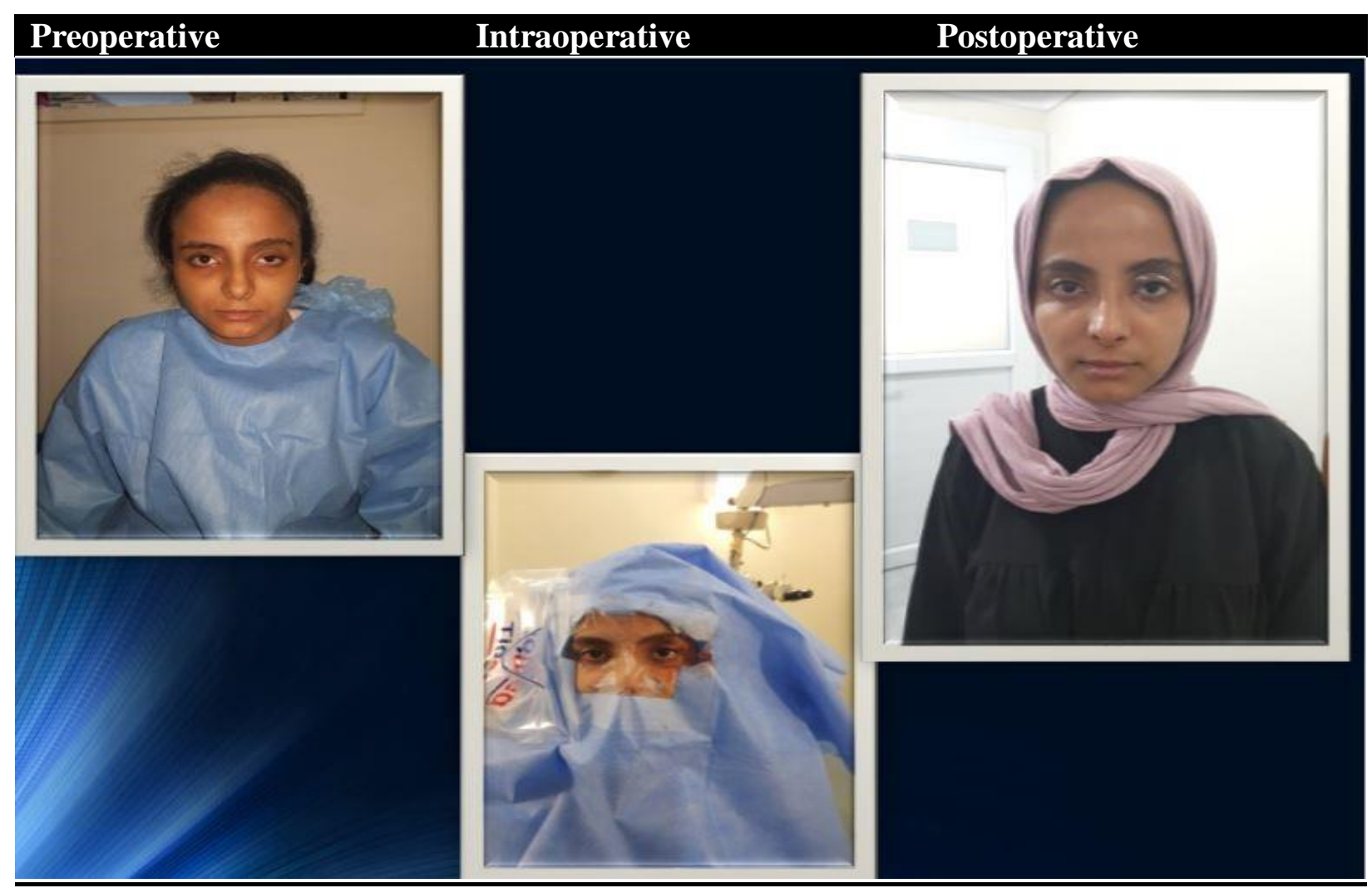

Figure (2): Pre/Postoperative pictures of one case

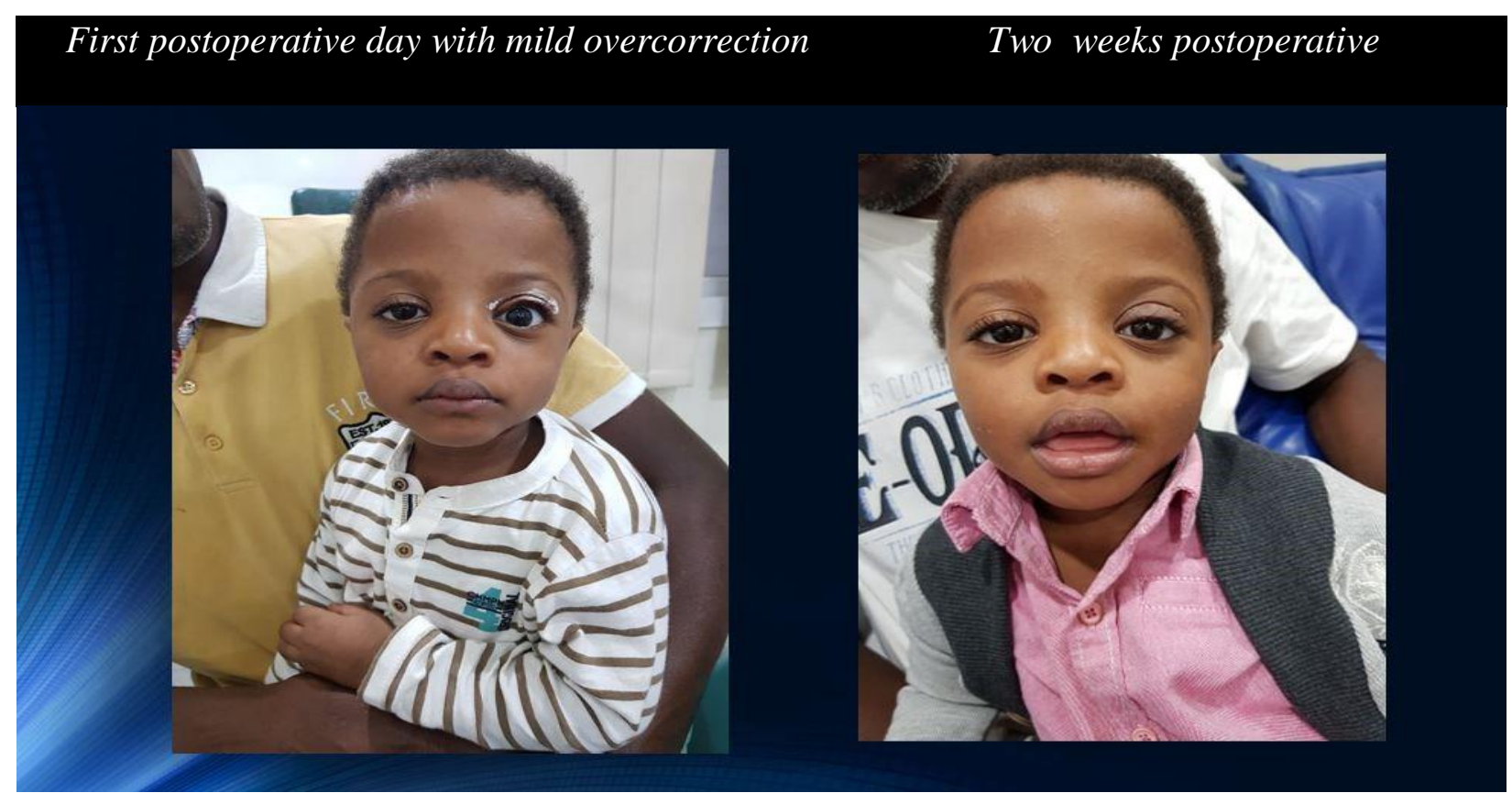

Figure (3) - Pre/Postoperative with mild overcorrection of one case 


\section{International Journal of Medical Science and Health Research}

Vol. 6, No. 01; 2022

ISSN: 2581-3366

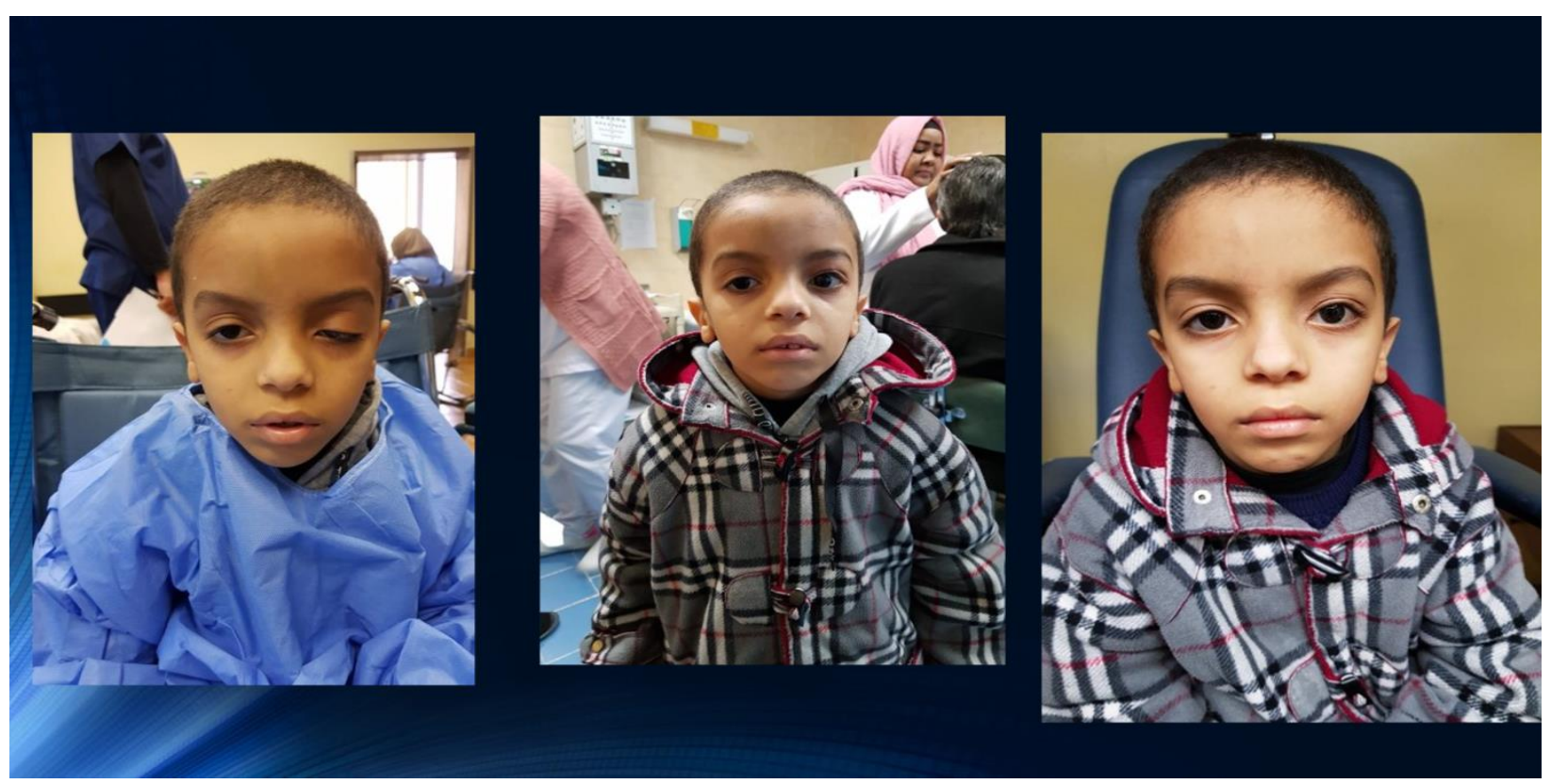

Figure (4) - pre/postoperative of one case

\section{Discussion}

Drooping of the upper eyelid is a common ophthalmic problem that is often encountered by ophthalmologists and represents either a functional or a cosmetic problem. Functionally, amblyopia happens in severe cases when the droopy eyelid covers the pupil resulting in obscured visual access. Cosmetically, the ptotic eyelid causes asymmetric appearance of both eyelids and inequality of both palpebral fissure openings.

The main goal of treatment of congenital ptosis is to restore the function of levator muscle, thus to prevent amblyopia in pediatric age group, but cosmosis of the eyelid gives the surgeon an opportunity through this procedure to produce symmetry in lid height, contour and eyelid crease.

The outcomes of blepharoptosis surgery have been defined primarily by change in the eyelid margin position relative to the cornea, with success defined as eyelid position or symmetry within $0.5,1$ or $1.5 \mathrm{~mm}$. Certainly, the primary goal of blepharoptosis surgery is to elevate a ptotic eyelid, so that measuring the change in eyelid position is a logical and appropriate outcome measure

Different techniques are available for management of congenital ptosis. In this study after patient evaluation and preoperative evaluation, levator tucking method was used. The surgery was performed under general anesthesia for the young age group and under general anesthesia for older group. The usual skin incision helped to expose the field properly. After orbicularis splitting, proper dissection, septum incision and retracting the fat, the levator muscle was tucked using 3non-absorbable sutures to make sure the long-lasting effect of these sutures. During the procedure, special attention was paid to avoid suture appearance from the conjunctival side to 


\section{International Journal of Medical Science and Health Research}

Vol. 6, No. 01; 2022

ISSN: $2581-3366$

guard against future complications of erosion. The ptotic lid was corrected in 19 eyes (85\%) (Over an average of six months of follow-up), under corrected in 2 cases (9\%) one of them with preoperative poor levator function (bothcases needed further tightness later on) and over corrected in one eye (5\%). Proper evaluation could not be guaranteed since the procedure was under general anesthesia and the levator function cannot be precisely expected postoperatively. These results were nearly similar to that Liu D who operated a larger number of patients (169) with different degrees and types of ptosis.

The minimal lid oedema resolved by the end of the first week in most of cases because the duration of surgery was short with minimal tissue destruction.

Puffy eyelid was noticed in one eye; mostly due to the bulky folded muscle in the small eyelid of a 4 years old child with severe ptosis which improved in 2 months. Therefore, the overall corrected cases with accepted cosmetic appearance were19 eyes (86\%). The results were consistent with that of Kumar and co-workers.

Inadequate lid closure was present in all cases during the post-operative period which improved in most of cases over 1-3 months

The rapid recovery and efficacy of the procedure could be explained by short operative time, no levator resection and no horns cutting which means more anatomical and effective results.

In this study there were no cases of exposure keratopathy.

\section{Conclusion}

In this procedure the levator muscle was not severed and the horns were not cut which means there was no tissue destruction and the anatomy of the eyelids was not disturbed that much. Consequently, more anatomical and physiological repair was achieved. Therefore, this technique is safe, fast, simple and effective for management of congenital ptosis.

\section{References}

Smith B, McCord CD, Baylis H. Surgical treatment of blepharoptosis. Am J Ophthalmol. 1969;68:92-9.

Sakol PJ, Mannor G, Massaro BM. Congenital and acquired blepharoptosis. Curr Opin Ophthalmol. 1999;10:335-9.

Langford JD, Linberg JV, Blaylock WK, Chao GM. Axial myopia in congenital ptosis: An animal model. Ophthal Plast Reconstr Surg. 1998;14:261-5.

12. Kao SC, Tsai CC, Lee SM, Liu JH. Astigmatic change following congenital ptosis surgery. Zhonghua Yi Xue Za Zhi (Taipei) 1998;61:689-93.

Anderson RL, Jordan DR, Dutton JJ. Whitnall's sling for poor function ptosis. Arch Ophthalmol. 1990;108:1628-32. 
Lin LK, Uzcategui N, Chang EL. Effect of surgical correction of congenital ptosis on amblyopia. Ophthal Plast Reconstr Surg. 2008 Nov-Dec. 24(6):434-6.

Bergin DJ. Management and surgery of congenital and acquired ptosis. Continuing Ophthalmic Video Education. 1990.

Berry-Brincat A, Willshaw H. Paediatric blepharoptosis: a 10-year review. Eye (Lond). 2009 Jul. 23(7):1554-9.

McMullan TF, Robinson DO, Tyers AG. Towards an understanding of congenital ptosis. Orbit. 2006;25:179-84.

Ben Simon GJ, Macedo AA, Schwarcz RM, Wang DY, McCann JD, Goldberg RA. Frontalis suspension for upper eyelid ptosis: Evaluation of different surgical designs and suture material. Am J Ophthalmol. 2005;140:877-85. 